\title{
Evaluation NO2 Detection Using Low-Cost Folded Path Photometer
}

\author{
Januar Arif Fatkhurrahman $^{1 \dagger}$, Puji Lestari ${ }^{2}$ \\ ${ }^{1}$ Master Degree of Environmental Engineering, Faculty of Civil \& Environmental \\ Engineering, Institut Teknologi Bandung, 40132, Bandung, Indonesia \\ ${ }^{2}$ Faculty of Civil and Environmental Engineering, Institut Teknologi Bandung, \\ Jl. Ganesha No.10, Bandung 40132, Indonesia \\ †Email: januarfa@gmail.com
}

\begin{abstract}
Nitrogen dioxide $\left(\mathrm{NO}_{2}\right)$ contributes to several impacts both for human health and the environment. Periodical measurement of $\mathrm{NO}_{2}$ at industrial and residential areas needs comprehensive and reliable instrumentation; longinterference-free measures with minimum maintenance and re-calibration. DOAS can be used as a direct measurement technique based on specific absorption characteristics of $\mathrm{NO}_{2}$ follow Beer-Lambert law. This research applies a low-cost folded path photometer for measurement $\mathrm{NO}_{2}$ in air. Cheap tubular acrylic used as a detection cell with a 3D printed framework makes it compact, modular, and flexible. Evaluation of the DOAS conducted by instrument test responses using $\mathrm{NO}_{2}$ gas. The estimated LOD was $\sim 1263 \mathrm{pb}$ using $2 \mathrm{~nm}$ resolution of the spectrometer and 6-meter detection cell length. Deviation of the DOAS estimated to be $0.8 \%$ at high concentration and $2.85 \%$ at a low concentration based on DOAS calibration. An intercomparison between methods used to evaluate instrument performance to measure $\mathrm{NO}_{2}$ using emission from a motorcycle with coefficient correlation (R) 0.649 for paired DOAS-ASTM D1607 Griesz Saltzmann Method 0.846 for paired DOAS-Electrochemical Gas Analyzer. This significant correlation is caused by different respond time between paired methods, while it is still comparable for $\mathrm{NO}_{2}$ measurement.
\end{abstract}

Keywords: DOAS, intercomparison, nitrogen dioxide, photoabsorption, spectrometer.

\section{$1 \quad$ Introduction}

Approximately 4.2 million death per year is caused by poor ambient air quality related to anthropogenic activities [1]. Nitrogen dioxide $\left(\mathrm{NO}_{2}\right)$, together with Sulfur dioxide $\left(\mathrm{SO}_{2}\right)$, Ozone $\left(\mathrm{O}_{3}\right)$, Carbon Monoxide (CO), Particulates, and Lead $(\mathrm{Pb})$ known as one of six criteria air pollutants as it may have an impact on health and ability to degrade ecosystems and agricultures quality [2]. $\mathrm{NO}_{2}$ can directly irritate the human respiratory system in concentrations $50-100 \mathrm{pm}$ in 30 -minutes exposure. $\mathrm{NO}_{2}$ may contribute to the development of asthma [3]. $\mathrm{NO}_{2}$ and other $\mathrm{NO}_{\mathrm{x}}$ react well with water, oxygen, and other chemicals in the atmosphere to form acid rain that may harm sensitive ecosystems such as aquatic ecosystems, forests, 
and agriculture regions [4]. A comprehensive and reliable data will be an excellent addition to these requirements. There are also specific needs for measurement instruments; long-interference-free measurements with minimum maintenance and re-calibration [5].

Testing laboratories, industry, and local governments use various methods to measure $\mathrm{NO}_{2}$ in the air. ASTM standards like Griesz Saltzmann are used in the testing laboratory to conduct accurate $\mathrm{NO}_{2}$ tests, while this test only results in single data in an hour test [6]. Absorption photometry can be used as a direct measurement technique based on specific absorption characteristics of $\mathrm{NO}_{2}$. Absorption of light would follow Beer-Lambert law below [7].

$$
\frac{[I]}{\left[I_{0}\right]}=e^{-\sigma l c} \text { or } c=\frac{1}{\sigma l} \ln \left(\frac{I_{0}}{I}\right)
$$

Where $I_{0}$ is the intensity of light that passing absorbance cell without $\mathrm{NO}_{2}$ analyte present, $I$ is the intensity of light that passing absorbance cell with $\mathrm{NO}_{2}$ analyte present, $\sigma$ is the analyte coefficient of extinction (absorption cross-section in $\mathrm{cm}^{-}$ ${ }^{2}$ molecule ${ }^{-1}$ for $\left.\mathrm{NO}_{2}\right), l$ is the path length of the $\mathrm{NO}_{2}$ detection cell $(\mathrm{cm}$ or m), and $c$ is the concentration of the $\mathrm{NO}_{2}$ within detection cell $\left(\right.$ molec cm$\left.{ }^{-3}\right)$. Arranging Eq.1, absorbance $\ln \left(\frac{I_{0}}{I}\right)$, can be measured using a spectrometer-based instrument with a typical precision of $\sim 3 \times 10^{-6}$. As precision has good agreement with path length, there are several aproaches to gain better precision. Several kilometers of the open-path system have been used to measure the pt scale in differential optical absorption spectroscopy (DOAS) [8, 9]. However, this method limits the determination of the spatial distribution of analyte concentration. Another approach, closed-path DOAS equipped with mirrors to fold the light directly through the path length $[10,11]$; the White cell is the most common, with typical 100 or more reflections. This White cell has the disadvantages of a long period of flushing time. This research describes a new approach, a low-cost folded path photometer for measurement $\mathrm{NO}_{2}$ in air. A cheap acrylic tube may replace expensive metallic detection cells like Aluminum since acrylic did not react with $\mathrm{NO}_{2}$. Two Molybdenum mirrors use in mirror modules at a $45^{\circ}$ angle. Construction can be compact enough as several meter path lengths may be folded in one-meter dimension as we fold the path length. A 3D printed material from PLA-based filament used as an entire path length framework made it easy to replicate in another place and further research. The design makes it possible to solve the spatial distribution problem of analyte in an open-path system. Direct absorption at $440 \mathrm{~nm}$ technique used as $\mathrm{NO}_{2}$ measurement using a typical LED available in the market. Measurement of other gas species in the air can be adopted in the future using this modular approach. 


\section{$2 \quad$ Method}

\subsection{Experimental Design}

Figure 1 is a schematic diagram of the folded path photometer measuring $\mathrm{NO}_{2}$ concentration in air based on Beer-Lambert law (Eq. 1). An air pump draws analyte with a constant 1 liter per minute volumetric flow through the detection cell. The sample enters the instrument through the particulate filter made of a glass microfiber filter. It prevents particles in the sample from interfering with the absorbance measurement. The sample air enters the detection cell, made by cylindrical acrylic tubes with $30 \mathrm{~mm}$ inside diameter and $90 \mathrm{~cm}$ long. At the end of each detection cell, two fixed mount Molybdenum mirrors with $45^{\circ}$ angle orientation were placed. Two-mirror connected with an air column $10 \mathrm{~cm}$ long, so the sample air flowed through them and entered the next detection cell. A total $600 \mathrm{~cm}$ path length can be acquired with a 4.5-liter total volume with six detection cell trains.

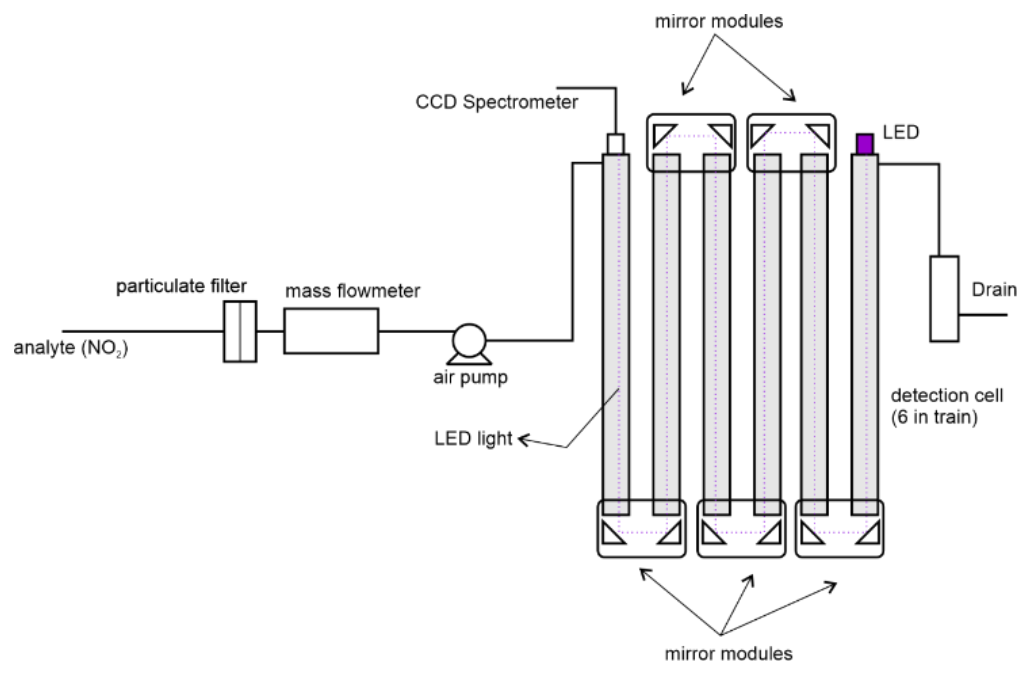

Figure 1 Schematic diagram of the folded path photometer for measuring $\mathrm{NO} 2$ concentration in air, picture adopted from [5].

The light source module used in this research emits light with proper wavelength to selectively absorb $\mathrm{NO}_{2}$ as an analyte. An LED with a wavelength range between $435 \mathrm{~nm}-465 \mathrm{~nm}$ was utilized to measure $\mathrm{NO}_{2}$. LED light powered by 3.4 DC voltage with 1 Ampere constant current, collimated using $15^{\circ}$ convex lens with $10 \mathrm{~cm}$ focal length at each end of the first and last detection cell. At the end of the optical train, the light was detected by Thorlabs CCS 200 CCD spectrometer. More than $90 \%$ of the light fraction will disappear using absorption spectroscopy since there is a reflection on the cell walls and mirrors [12]. These 
losses have little impact on the measurement since they remain at the constant condition of $I_{0}\left(\mathrm{NO}_{2}\right.$ scrubbed $)$ and $I\left(\mathrm{NO}_{2}\right.$ present $)$. The concentration of the $\mathrm{NO}_{2}$ as the analyte is calculated based on Beer-Lambert law.

\subsection{Calibration of CCD Spectrometer}

Collimated mercury lamp used to analyze the relationship between diffracted light wavelength and pixel number of the CCD camera on Thorlabs CCS 200. Mercury lamp has several lines in the spectral region between $253 \mathrm{~nm}-579 \mathrm{~nm}$ [13]; Figure S1 describes the calibration of the CCD spectrometer.

\subsection{Experimental Procedure}

In DOAS measurement, background spectrum, $I_{0}(\lambda)$ as blank and analyte spectrum, $I(\lambda)$ needs to be measured. A zero-gas containing $\mathrm{N}_{2}$ is used as blank since it does not have interfering $\mathrm{NO}_{2}$ absorption in $435 \mathrm{~nm}-465 \mathrm{~nm}$. Series of $\mathrm{NO}_{2}$ gas calibration standard was used as validation measurement, analyzed using the correlative statistic. Co-location measurement deploys by measure three different methods between DOAS, electrochemical gas sensor Alphasense NO2B4, and ASTM D1607 Griesz Saltzmann as a comparison. Both data were analyzed for the Griesz Saltzmann method, recorded within the same period, and analyzed using correlative analysis.

\section{$3 \quad$ Result and Discussion}

\subsection{Spectral Resolution}

Spectral resolution from instrument measured using line spectra using mercury lamp. Mercury lamp has primary line spectra at $546 \mathrm{~nm}$ and $578 \mathrm{~nm}$, while secondary spectra at $366 \mathrm{~nm}, 403 \mathrm{~nm}, 435.8 \mathrm{~nm}, 1012 \mathrm{~nm}, 1125 \mathrm{~nm}, 1362 \mathrm{~nm}$, $1525 \mathrm{~nm}, 1688 \mathrm{~nm}$, and 1692 [14]. At the evaluation wavelength range $435 \mathrm{~nm}-$ $465 \mathrm{~nm}$, mercury lamps have strong line emissions at $435.8 \mathrm{~nm}$ - line spectra at evaluation range in Thorlabs CCS 200 shown in figure S2. Thorlabs CCS 200 have resolution $<2 \mathrm{~nm}, 1.1 \mathrm{~nm}$ deviation of the peak spectra indicate this spectrometer is in proper condition to measure absorbance photometry. According to [15], Bruker 120M FT Fourier transform spectrometer used at 0.01 $\mathrm{nm}$ resolution at $240 \mathrm{~nm}$ and $0.2 \mathrm{~nm}$ at $1000 \mathrm{~nm}$ to measure $\mathrm{NO}_{2}$ absorption crosssection in high resolution used as reference. The cheap blue LED used in this research may have a limited wavelength region compared with previous research. Figure 3(a) showed a high resolution of $\mathrm{NO}_{2}$ absorption cross-section from Vandaele compared with the evaluation range of this research at $435 \mathrm{~nm}-465$ $\mathrm{nm}$, overlayed with typical intensity of blue LED absorbance. 


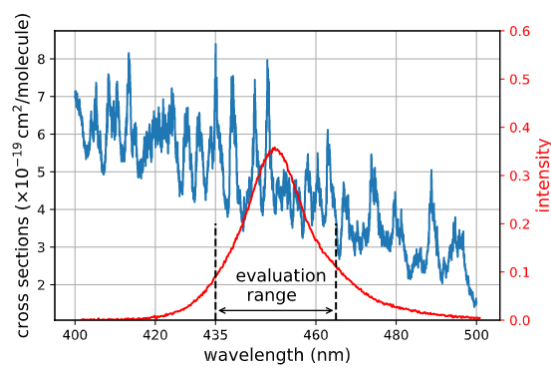

(a)

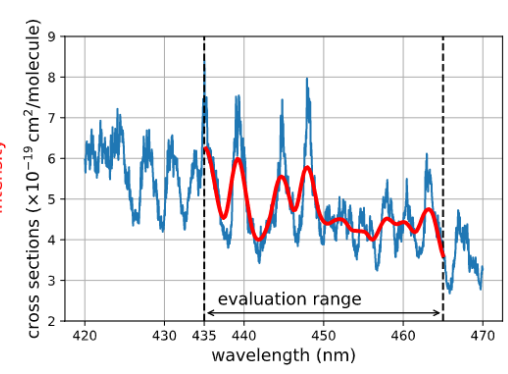

(b)

Figure 2 (a) Evaluation range of $\mathrm{NO}_{2}$ measurement, (b) Gaussian fitting between different instrument resolution.

The Thorlabs CCS 200 absorption cross-section needs to be adapted to the low resolution of the instrument. Figure 3(b) show that each wavelength range is shown as normal distribution pattern, gaussian fitting may be used as absorption cross-section fitting between two different resolutions. Measured $\mathrm{NO}_{2}$ concentration can be calculated using least square fitting between measured intensity based on Beer-Lambert law and modeled optical density $\sigma_{i}^{\prime}(\lambda)$ based on absorption cross-section reference $\sigma_{i, L i t}^{\prime}[16]$, as seen on Eq.2. Optical density $\tau$, calculated as logaritmic value of measured spectrum $I(\lambda)$ with background spectrum $I_{0}(\lambda)$.

$$
\tau=\underbrace{\ln \frac{I_{0}(\lambda)}{I(\lambda)}}_{\text {measurement }}=\underbrace{\sum_{i} \sigma_{i, \text { Lit }}^{\prime}(\lambda) \cdot \overline{c_{\boldsymbol{l}}} \cdot \boldsymbol{L}}_{\text {model }}+\underbrace{\boldsymbol{R}(\lambda)}_{\text {residu }}
$$

Using the least square method, we may minimize residual value $R(\lambda)$, between measurement and model, then $\mathrm{NO}_{2}$ mixing ratio $\overline{c_{l}}$ can be calculated in molecule per volume. $\mathrm{NO}_{2}$ concentration in pm or pb is calculated as a mixing ratio towards the number of molecules per volume as an ideal gas.

\subsection{Limit Detection}

The detection limit (LOD) is the lowest concentration that can be measured with statistical significance through a given analytical procedure [17] and can be estimated using $\mathrm{Eq}(3)$.

$$
L O D=\mu+3 S D
$$

Blank analyte measured as LOD estimation with data can be seen in Figure 4 data gathered from 1000 blank analyte measurements. 


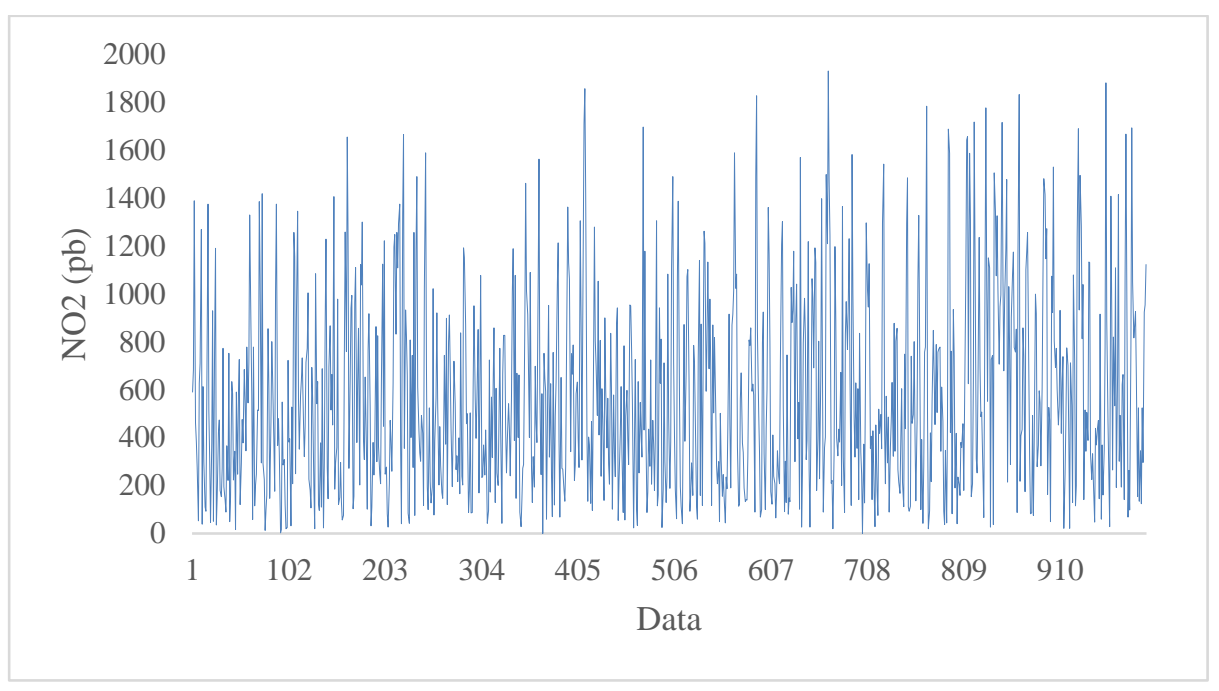

Figure 3 Evaluation of the LOD based on blank analyte

Theoretically, cell detection length would affect LOD and be affected by the spectrometer's resolution. Ten times lower resolution used in this research than Vandaele's [15] may imply high LOD compared with a theoretical detection limit of $100 \mathrm{pb}$ for a 6-meter detection length cell. Based on Eq(3) LOD of the DOAS estimated at $\sim 1263 \mathrm{pb}$, this LOD is in step with Devine's research using Ocean Optics USB 4000 spectrometer with a similar resolution with Thorlabs CCS 200 [18]. With this LOD, calibration of the DOAS may use two points calibrations at a higher concentration than $1.5 \mathrm{pm}$.

\subsection{DOAS Calibration}

Calibration is a process to verify and evaluate the accuracy of the DOAS. Several calibration techniques may be used, [19] calibrate DOAS using correlation analysis based on certified reference instruments. [20] use gas calibration standards to check the accuracy of the DOAS. In this research, two different concentrations of $\mathrm{NO} 2$ are used, $50 \mathrm{pm}$ and $3.5 \mathrm{pm}$, each represents high concentration and low concentration [21]. A Zephyr gas dilution system was used to dilute $\mathrm{NO}_{2}$ using $\mathrm{N}_{2}$ to get a $\mathrm{NO}_{2}$ concentration of $3.5 \mathrm{pm}$. Each concentration was measured at the same condition, calibration data seen in Figure 5. With the uncertainty of the gas calibration standard 5\% (marked as the uper limit and lower limit in Figure 5), ten data measurements show that the average concentration of high concentration gas calibration standard is $50.4+0.85 \mathrm{pm} 3.4 \pm 0.32 \mathrm{pm}$ for low concentration with $95 \%$ confidence level. From this measurement, the deviation of the DOAS estimated to be $0.8 \%$ at high concentration and $2.85 \%$ at low concentration. 


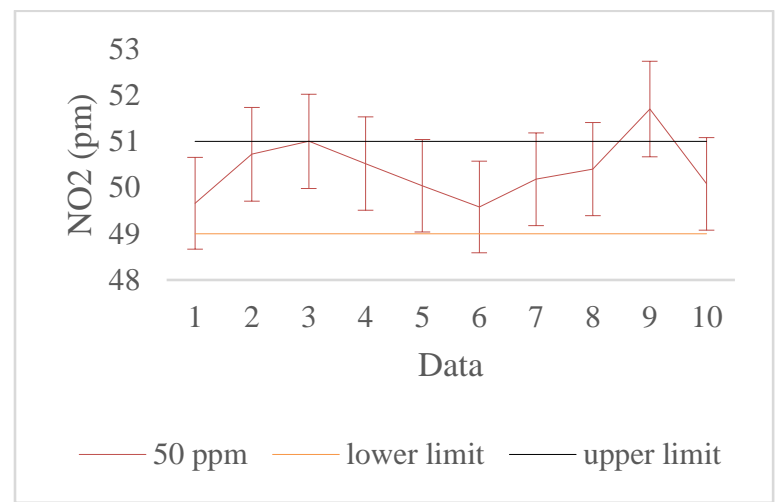

(a)

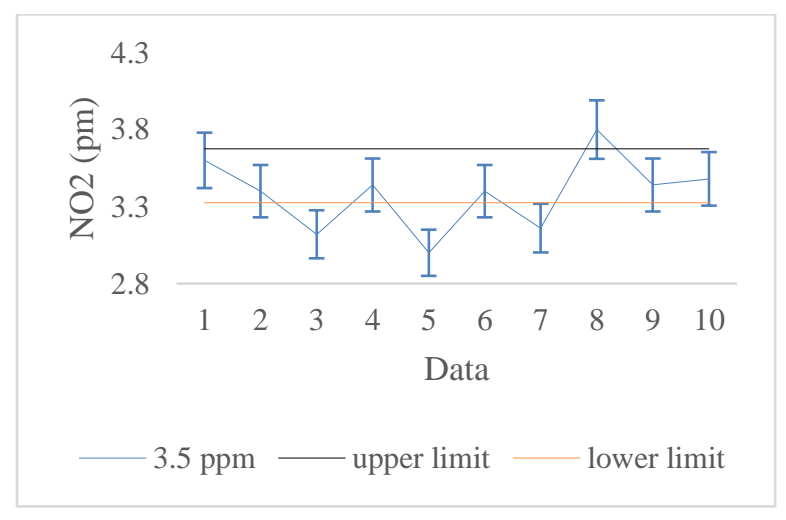

(b)

Figure 4 DOAS calibration using (a) 50 pm-high concentration and (b) 3.5 pmlow concentration

\subsection{Precision Measurement}

Intercomparison and co-location analysis between DOAS, electrochemical gas analyzer, and ASTM D1607 reference method was used as a precision test. As a $\mathrm{NO}_{2}$ source, we used $\mathrm{NO}_{2}$ emission from the motorcycle, both DOAS, electrochemical gas analyzer, and ASTM D1607 Griesz Saltzmann data plotted in parallel, as shown in Figure 6. 


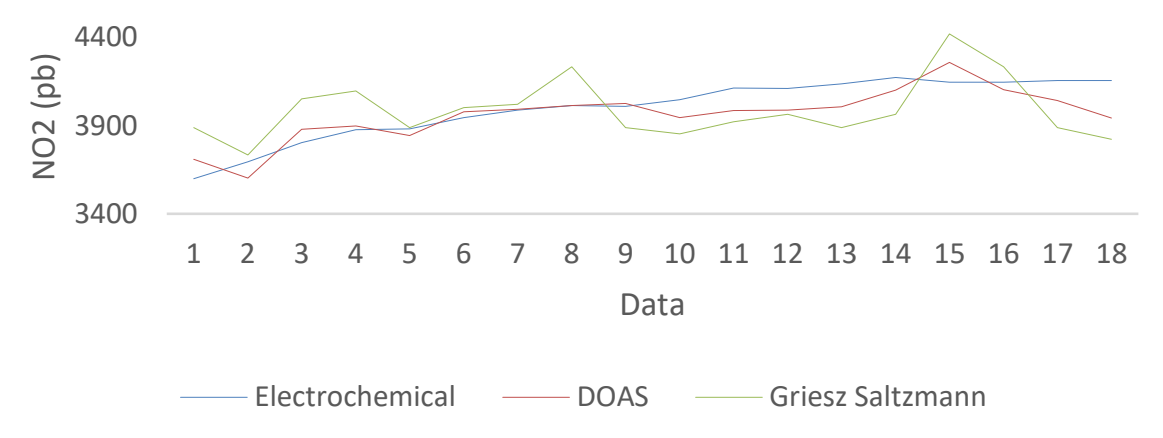

Figure 5 Intercomparison data between DOAS, electrochemical gas analyzer, and ASTM D1607 Griesz Saltzmann

Statistically, paired sample test was acquired to hypothesize the average measurement between two paired methods; DOAS - Electrochemical Gas Analyzer and DOAS - ASTM D1607 Griesz Saltzmann, as seen in table S3. DOAS - Electrochemical Gas Analyzer seems to be more correlated than DOAS - ASTM D1607 Griesz Saltzmann identified by higher coefficient correlation on it, this significance correlation in between paired method caused by different response time between method as measurement data, DOAS have $150 \mathrm{~ms}$ respond time compared with 90 seconds using electrochemical gas analyzer, while ASTM D1607 Griesz Saltzmann has 10 minutes response time for each measured data. As a result, another intercomparison needs to be conducted using an instrument with a short response time compared to DOAS [22]. Based on the paired sample test, we can acquire the hypothesis that both paired methods were comparable by seeing Sig. (2-tailed) a result that higher than $<0.05$ indicates no average difference between two paired measurement data and concluded that both paired methods were comparable.

\section{Conclusions}

There is a good intensity response in DOAS to detect NO2 in the air as seen on the absorbance response in the DOAS instrument. With $2 \mathrm{~nm}$ resolution of the spectrometer and 6-meter detection cell length, this setup has a detection limit (LOD) $1263 \mathrm{pb}$. Deviation of the DOAS estimated to be $0.8 \%$ at high concentration and $2.85 \%$ at a low concentration based on DOAS calibration. An intercomparison between methods used to evaluate instrument performance to measure $\mathrm{NO}_{2}$ using emission from the motorcycle with coefficient correlation (R) 0.649 for paired DOAS-ASTM D1607 Griesz Saltzmann Method 0.846 for paired DOAS-Electrochemical Gas Analyzer. This different significance correlation is caused by different response times between paired methods. Even 
paired sample test indicates both paired methods were comparable for $\mathrm{NO}_{2}$ measurement.

\section{Acknowledgments}

Funding of this research is supported by Lembaga Pengelolala Dana Pendidikan (LPDP) scholarship as Indonesia Endowment Fund for Education. The authors express their gratitude to Center of Industrial Pollution Prevention Technology (BBTPI) as their laboratory supporting this Thesis research.

\section{References}

[1] W. World Health Organization, “Air pollution," 2021. [cited May 27, 2021]. Available from https://www.who.int/health-topics/air-pollution\#tab=tab_2.

[2] P. Saxena, S. Sonwani, P. Saxena, and S. Sonwani, "Primary Criteria Air Pollutants: Environmental Health Effects," in Criteria Air Pollutants and their Impact on Environmental Health, Springer Singapore, 2019, p. 49-82.

[3] A. Faustini, R. Rap, and F. Forastiere, "Nitrogen dioxide and mortality: Review and meta-analysis of long-term studies," European Respiratory Journal, vol. 44, no. 3. European Respiratory Society, p. 744-753, Sep. 01, 2014, doi: 10.1183/09031936.00114713.

[4] EPA, "Basic Information about NO2 | Nitrogen Dioxide (NO2) Pollution | US EPA," www.epa.gov, 2016. [cited Jun. 03, 2021]. Available from : https://www.epa.gov/no2-pollution/basic-information-about-no2.

[5] J. W. Birks et al., "Folded tubular photometer for atmospheric measurements of NO\&amp;lt;sub\&amp;gt;2\&amp;lt;/sub\&amp;gt; and NO," Atmos. Meas. Tech., vol. 11, no. 5, p. 2821-2835, May 2018, doi: 10.5194/amt-11-2821-2018.

[6] A. M. Simbolon, J. A. Fatkhurrahman, A. Mariani, I. R. J. Sari, Syafrudin, and Sudarno, "Challenge of integrated low-cost emission monitoring system into a digital information system," in IOP Conference Series: Earth and Environmental Science, Jan. 2021, vol. 623, no. 1, p. 012076, doi: 10.1088/1755-1315/623/1/012076.

[7] U. Platt and J. Stutz, "Interaction of Molecules with Radiation," in Differential Optical Absorption Spectroscopy, Springer Berlin Heidelberg, 2008, p. 77-90.

[8] P. P. Geiko, S. S. Smirnov, and I. V. Samokhvalov, "Open path measurement of atmospheric pollutants using DOAS method," in 22nd International Symposium on Atmospheric and Ocean Optics: Atmospheric 
Physics, Nov. 2016, vol. 10035, p. 100353N, doi: 10.1117/12.2248817.

[9] R. Jimenez, H. van den Bergh, and B. Calpini, "DOAS as an Analytical Tool for Effective Air Pollution Management," Jan. 1999.

[10] H. Edner, P. Ragnarson, S. Spännare, and S. Svanberg, "Differential optical absorption spectroscopy (DOAS) system for urban atmospheric pollution monitoring," Apl. Opt., vol. 32, no. 3, p. 327, Jan. 1993, doi: 10.1364/ao.32.000327.

[11] X. Yi, Z. Zhang, and P. Smith, "Real-time measurements of landfill atmospheric ammonia using mobile white cell differential optical absorption spectroscopy system and engineering aplications," J. Air Waste Manag. Assoc., vol. 71, no. 1, p. 34-45, 2021, doi: 10.1080/10962247.2020.1820405.

[12] A. Axelevitch, B. Gorenstein, and G. Golan, "Investigation of Optical Transmission in Thin Metal Films," Phys. Procedia, vol. 32, p. 1-13, 2012, doi: 10.1016/j.phpro.2012.03.510.

[13] J. Reader, C. J. Sansonetti, and J. M. Bridges, "Irradiances of spectral lines in mercury pencil lamps," Apl. Opt., vol. 35, no. 1, p. 78, 1996, doi: 10.1364/ao.35.000078.

[14] C. D. Elvidge, D. M. Keith, B. T. Tuttle, and K. E. Baugh, "Spectral identification of lighting type and character," Sensors, vol. 10, no. 4, p. 3961-3988, Apr. 2010, doi: 10.3390/s100403961.

[15] A. C. Vandaele et al., "Measurements of the NO2 absorption cross-section from $42000 \mathrm{~cm}-1$ to $10000 \mathrm{~cm}-1(238-1000 \mathrm{~nm})$ at $220 \mathrm{~K}$ and $294 \mathrm{~K}, " J$. Quant. Spectrosc. Radiat. Transf., vol. 59, no. 3-5, p. 171-184, Mar. 1998, doi: 10.1016/S0022-4073(97)00168-4.

[16] J. M. Nasse, P. Eger, D. Pöhler, S. Schmitt, U. Frieß, and U. Platt, "Recent improvements of long-path DOAS measurements: impact on accuracy and stability of short-term and automated long-term observations," Atmos. Meas. Tech., vol. 12, no. 8, p. 4149-4169, Aug. 2019, doi: 10.5194/amt-124149-2019.

[17] P. Konieczka, "Validation and Regulatory Issues for Sample Preparation," Compr. Sampl. Sample Prep., vol. 2, p. 699-711, Jan. 2012, doi: 10.1016/B978-0-12-381373-2.00064-8.

[18] B. Devine, "A Miniaturised Spectrometer Device for the Detection of Nitrogen Dioxide in an Urban Environment A miniaturised spectrometer device for the detection of Nitrogen Dioxide in an urban environment," 2013, doi: 10.21427/D79594. 
[19] J. A. Fatkhurrahman et al., "DOAS Calibration Technique for SO2 Emission Measurement Based on $\mathrm{H} 2 \mathrm{SO} 4$ and Na2SO3 Reaction," J. Ris. Teknol. Pencegah. Pencemaran Ind., vol. 11, no. 1, p. 36-45, May 2020, doi: 10.21771/jrtpi.2020.v11.no1.p36-45.

[20] F. Margelli and G. Giovanelli, "Calibration And Validation Methods For DOAS Remote Sensing Systems," WIT Trans. Ecol. Environ., vol. 53, Jun. 2002, doi: 10.2495/AIR020381.

[21] O. US EPA, EMC Conditional Test Methods (CTM-022). United States, 1995.

[22] T. Zhang, M. Wooster, D. C. Green, and B. Main, "A Mathematical Aproach to Merging Data from Different Trace Gas/Particulate Sensors Having Dissimilar (T90) Response Times: Aplication to Fire Emission Factor Determination," Aerosol Air Qual. Res., vol. 20, no. 2, p. 281-290, Feb. 2020, doi: 10.4209/AAQR.2019.02.0061. 